\title{
Plasma lipoproteins, lipid transport, and atherosclerosis: Recent developments
}

\author{
N. E. MILLER \\ From the Department of Chemical Pathology and Metabolic Disorders, St Thomas's Hospital \\ Medical School, London, UK
}

The subjects of normal and disordered lipid metabolism were reviewed comprehensively in a multiauthor supplement to this Journal in 1973 (McGowan and Walters, eds). Since that time considerable progress has been made in our understanding of the pathophysiology of plasma lipoproteins and their relationship to atherosclerosis. Two particularly notable developments have been the identification and characterisation of a receptor-mediated mechanism, present in all peripheral tissues so far examined, for the uptake and catabolism of low density lipoprotein (LDL), and the recognition of the predictive power of the plasma high density lipoprotein (HDL) cholesterol concentration in relation to coronary heart disease (CHD). In addition, epidemiological, genetic, and metabolic studies have provided greater insight into the nature of the primary (familial) dyslipoproteinaemias. This has necessitated a partial revision of earlier approaches to the classification of these conditions, based on the associated lipoprotein phenotype, to a system based more on the underlying genetic and biochemical abnormalities.

This review will be divided into four areas of interest to the clinical pathologist: normal lipid transport; the primary dyslipoproteinaemias; the secondary dyslipoproteinaemias; and the relationship of lipoproteins to atherogenesis.

\section{Normal plasma lipid transport}

Early studies of the transport of cholesterol and triglyceride as separate entities led the way to a more integrated approach, with the realisation that the metabolism of the different plasma lipids is largely inseparable from the synthesis, interconversion, and catabolism of the lipoproteins of which they are components. The physicochemical characteristics of the major lipoprotein classes in normal human plasma are presented in Table 1. Each class is itself heterogeneous, being composed of a spectrum of

Received for publication 31 January 1979 particles of differing composition, size, and density. The largest particles, chylomicrons, are normally absent in the fasting state. In normal fasting plasma, the majority of triglyceride resides in the very low density lipoproteins (VLDL), whereas most of the cholesterol is in LDL. The general structure of plasma lipoproteins is that of a 'pseudomicelle', composed of an outer surface coat of specific peptides (apoproteins) and polar lipids (unesterified cholesterol, phospholipid) and an inner core of non-polar lipids (cholesterol ester, triglyceride). The apoproteins are able to occupy this interfacial position by virtue of their amphipathic helices (in which polar and non-polar groups lie on opposite sides of the molecule) (Bradley and Gotto, 1978). They play critical roles in maintaining the structure of the particles and in regulating at least two enzymes involved in their metabolism: lecithin: cholesterol acyltransfrase (LCAT) and lipoprotein lipase.

The major functions of the plasma lipoproteins are: (i) to transport endogenously synthesised and exogenous (absorbed dietary) glyceride, an important energy source, to sites of utilisation and storage; and (ii) to transport cholesterol, an essential structural component of cell membranes, between sites of absorption, synthesis, catabolism, and excretion. Dietary glyceride and cholesterol enter the circulation via the mesenteric lymphatics as components of newly synthesised (nascent) chylomicrons. De novo synthesis of glyceride (from glucose and plasma free fatty acids) and cholesterol (from acetate) occurs mostly in the liver, where they are secreted into the circulation as components of VLDL. Both chylomicrons and VLDL contain apoprotein $B$ as an essential structural component. Nascent chylomicrons are also rich in apoproteins AI and AII, but these are only loosely bound to the particle and rapidly transfer to HDL after entering the circulation (Schaefer et al., 1978).

The initial stages in the catabolism of chylomicrons and VLDL appear to be similar and can therefore be considered together. There is evidence that both 
Table 1 Physicochemical characteristics of the major plasma lipoprotein classes in man

\begin{tabular}{|c|c|c|c|c|c|c|}
\hline Class & Density $(\mathrm{g} / \mathrm{ml})$ & $S f^{*}$ & $\begin{array}{l}\text { Electrophoretic } \\
\text { mobility } \dagger\end{array}$ & $\begin{array}{l}\text { Particle diameter } \\
(\mathrm{nm})\end{array}$ & $\begin{array}{l}\text { Major lipids ( } \% \text { of } \\
\text { total mass) }\end{array}$ & Apoproteins \\
\hline $\begin{array}{l}\text { Chylomicrons } \\
\text { VLDL } \\
\text { IDL }\end{array}$ & $\begin{array}{l}<0.95 \\
0.95-1.006 \\
1.006-1.019\end{array}$ & $\begin{array}{l}>400 \\
20-400 \\
12-20\end{array}$ & $\begin{array}{l}\text { Origin } \\
\text { Pre- } \beta \\
\beta\end{array}$ & $\begin{array}{l}120-1100 \\
30-90 \\
25-30\end{array}$ & $\begin{array}{l}\text { Glyceride }(85 \%) \\
\text { Glyceride }(50 \%) \\
\text { Glyceride }(35 \%) \\
\text { Cholesterol ester } \\
(25 \%)\end{array}$ & $\begin{array}{l}\text { C, B, A } \\
\text { C, B, E } \\
\text { B, C, E }\end{array}$ \\
\hline LDL & $1.019-1.063$ & $0-12$ & $\beta$ & $21-25$ & $\begin{array}{l}\text { Cholesterol ester } \\
(40 \%)\end{array}$ & B \\
\hline HDL $\ddagger \S$ & $1 \cdot 063-1 \cdot 21$ & - & $a$ & $7-10$ & $\begin{array}{l}\text { Phospholipid }(25 \%) \\
\text { Cholesterol ester } \\
(15 \%)\end{array}$ & $\mathbf{A}, \mathbf{C}, \mathbf{E}$ \\
\hline
\end{tabular}

*Flotation rate in Svedberg units $\left(10^{-13} \mathrm{~cm} / \mathrm{s} / \mathrm{dyne} / \mathrm{g}\right)$ in $\mathrm{NaCl}$ solution of density $1.063 \mathrm{~g} / \mathrm{ml}$ at $26^{\circ} \mathrm{C}$.

†Paper or agarose gel electrophoresis.

†Te composition of newly secreted chylomicrons and HDL differs from that of the plasma lipoproteins (see text).

§Plasma HDL is composed of two major subclasses, $\mathrm{HDL}_{2}(1 \cdot 063-1 \cdot 125 \mathrm{~g} / \mathrm{ml})$ and $\mathrm{HDL}_{3}(1 \cdot 125-1 \cdot 21 \mathrm{~g} / \mathrm{ml})$, the former having a greater cholesterol and apoprotein $\mathrm{C}$ content.

lipoproteins may be secreted devoid of $\mathrm{C}$ apoproteins, and that these are acquired only after entering the circulation from HDL (Havel, 1978). After transfer from HDL, the CII apoprotein activates lipoprotein lipase, located in the capillary bed of several tissues, resulting in the hydrolysis of chylomicron and VLDL triglyceride. The free fatty acids so released are in turn either oxidised (mostly in skeletal muscle and myocardium) or re-esterified and stored (mainly in adipose tissue). Lipoprotein lipase is stimulated by insulin. This contrasts with the hormone-sensitive lipase of adipose tissue, responsible for intracellular triglyceride hydrolysis, which is inhibited by insulin and stimulated by noradrenaline. Another important property of lipoprotein lipase is that it can be released into the circulation by intravenous heparin, a property which provides the basis of a clinical test of its presence and activity (serum post-heparin lipolytic activity).

As triglyceride is removed from the cores of chylomicrons and VLDL they appear to acquire cholesterol esters. These are not generated in the particles themselves, however, but are transferred from HDL, where they are produced from cholesterol and lecithin by the action of LCAT, an enzyme secreted by the liver, associated with HDL, and activated by apoprotein AI. The other product of the LCAT reaction, lysolecithin, is transferred to albumin. Recent studies have suggested that the transfer of cholesterol esters from HDL to triglyceride-rich lipoproteins may be accompanied by a similar movement of apoprotein E from HDL. Continued hydrolysis of the triglyceride of chylomicrons and VLDL progressively reduces their lipid content and size (with a corresponding increase in density), resulting in the formation of smaller lipoproteins of lower triglyceride/cholesterol ester ratio: 'chylomicron remnants' derived from chylo- microns, and intermediate density lipoproteins (IDL) derived from VLDL.

The progressive decrease in the diameter (and therefore in the surface area) of chylomicrons and VLDL during catabolism is permitted by the release of surface components (unesterified cholesterol, phospholipid, and $\mathrm{C}$ apoproteins) in particulate form. These enter the HDL density range and appear to fuse with $\mathrm{HDL}_{3}$ particles, converting them to $\mathrm{HDL}_{2}$ (Patsch et al., 1978). The $\mathrm{C}$ apoproteins are thus gradually returned to the HDL from which they were originally derived. In this way HDL acts as a flexible reservoir of these peptides. The precise roles of apoproteins CI and CIII are unresolved, although effects on lipoprotein lipase and LCAT have been noted in vitro. Apoprotein B is non-exchangeable and remains as an obligatory structural component of triglyceride-rich lipoproteins during their catabolism.

Chylomicron 'remnants' are rapidly cleared from the circulation by the liver. A proportion of IDL may have a similar fate, but under normal circumstances at least the great majority is converted, again probably in the liver, to LDL. In normal human subjects all LDL is derived from VLDL catabolism in this way (Sigurdsson et al., 1975). The main differences between IDL and LDL are a lower triglyceride content, a correspondingly greater cholesterol content, and an absence of $C$ and $E$ apoproteins in the latter (apoprotein $B$ being the only protein component of LDL). The removal of triglyceride from IDL may be a function of hepatic triglyceride lipase. This enzyme shares with lipoprotein lipase the property of being heparinreleasable but differs in not requiring apoprotein CII and in not being inhibited by protamine or $1 \mathrm{M} \mathrm{NaCl}$.

The removal of LDL from the circulation occurs largely by a receptor-mediated process in peripheral 
tissues, although some LDL catabolism probably occurs additionally in the liver. Evidence for the existence of cell surface receptors for apoprotein B was first provided by Goldstein and Brown (1974) in studies of cultured human skin fibroblasts. The receptors were subsequently shown to be protein in nature and to be localised in thickened and indented regions of the plasma membrane ('coated pits') specialised for rapid invagination and vesicle formation. Subsequent studies have confirmed the presence of similar receptors in cultured smooth muscle cells, vascular endothelium, adipocytes, adrenocortical cells, and lymphocytes. Binding of LDL to the receptors is essentially irreversible, resulting in the internalisation of the lipoprotein by endocytosis and its incorporation into secondary lysosomes. Here the B apoprotein is degraded to trichloroacetic acid-soluble fragments, which are released from the cell. The cholesterol ester component is hydrolysed, and the resultant unesterified cholesterol has at least three effects: (i) inhibition of cellular cholesterol synthesis through suppression of the activity of 3-hydroxy-3-methylglutaryl coenzyme A reductase; (ii) enhancement of cholesterol esterification by activation of microsomal fatty
acyl-CoA cholesterol acyltransferase; and (iii) suppression of LDL receptor synthesis, thereby reducing further LDL uptake. The receptor-mediated catabolism of LDL has been reviewed in detail by Goldstein and Brown (1977) and is summarised in Figure 1.

Recently, it has been demonstrated that a minor subclass of $\mathrm{HDL}_{2}$, so-called HDL-I, also has a high affinity for the LDL receptor, a property conferred upon it by the presence of apoprotein $E$ (Innerarity et al., 1978). Competition between LDL and HDL for the receptors has been demonstrated in vitro, but the physiological significance of this phenomenon is not yet clear (Miller et al., 1977a).

With the possible exception of the nervous system, all body tissues so far examined have been shown both to possess LDL receptors and to synthesise cholesterol from acetate. Only hepatocytes, however, are able to catabolise cholesterol (to the primary bile acids, chenodeoxycholic and cholic acids) in quantitatively significant amounts. Direct elimination of cholesterol from the body also occurs mostly by way of secretion into the bile. Smaller amounts of cholesterol are converted to steroid hormones and are lost by desquamation of

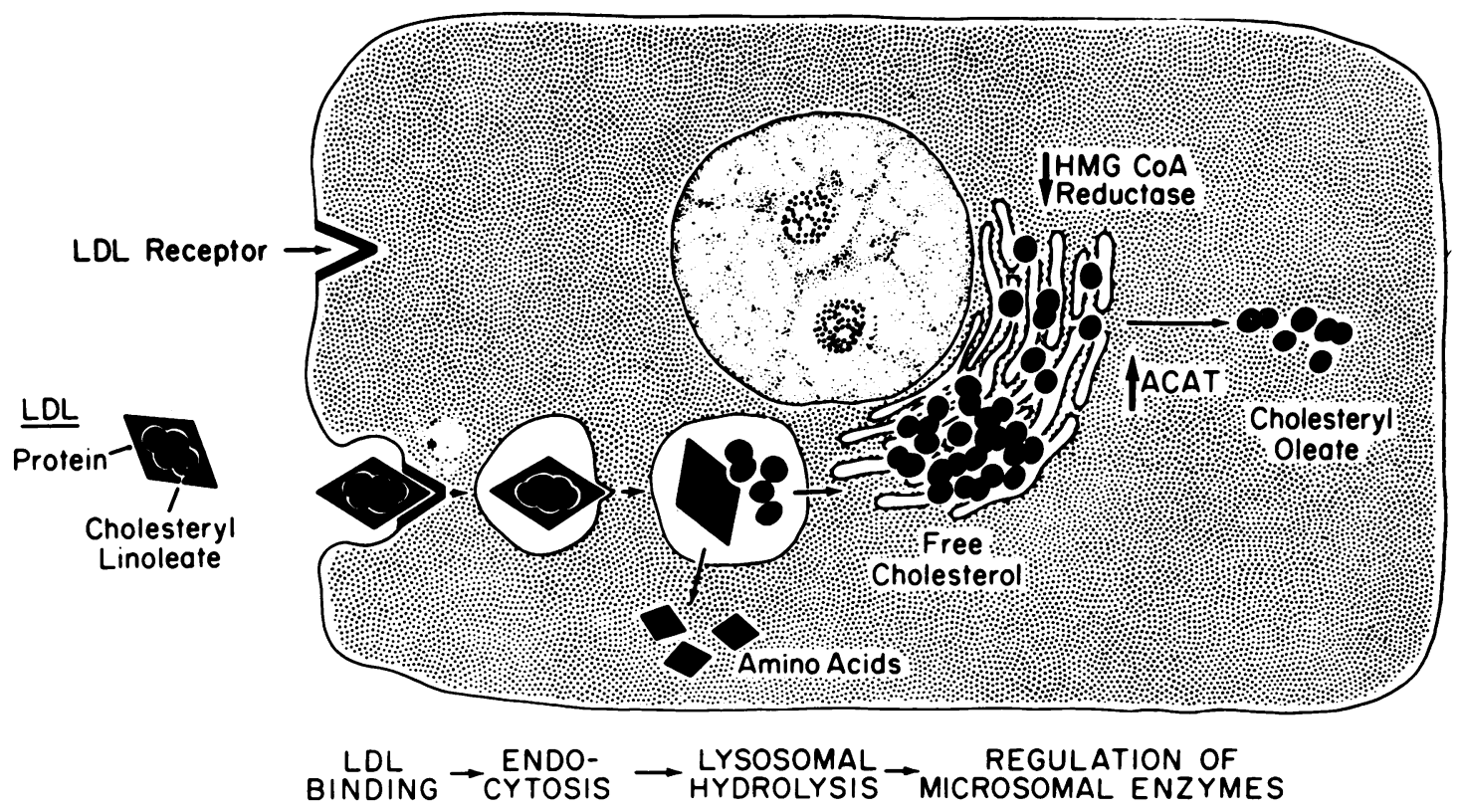

Fig. 1 Low density lipoprotein receptor pathway in cultured human fibroblasts. HMG CoA = 3-hydroxy-3methylglutaryl coenzyme A reductase; $A C A T=$ acyl-CoA: cholesterol acyltransferase. Reproduced, in modified form, from Goldstein and Brown (1977), with the permission Annual Reviews Inc. 
epithelial cells of the skin and alimentary tract.

The transport of cholesterol, derived from LDL uptake and endogenous synthesis, from peripheral tissues to the liver for catabolism and excretion was suggested by Glomset (1970) to be a function of HDL acting in concert with LCAT. Although proof of this concept is still awaited, this remains the most likely mechanism of centripetal (or reverse) cholesterol transport. The main supporting evidence is as follows: HDL is unique among the major plasma lipoproteins in promoting a net efflux of cholesterol from cultured peripheral cells (eg, fibroblasts and smooth muscle) and erythrocytes in vitro; HDL provides the optimum substrate for LCAT; HDL and LCAT together are much more effective in promoting cholesterol efflux from erythrocytes than is HDL alone (Glomset, 1970); cultured hepatocytes have been shown to take up and hydrolyse HDL protein (Nakai et al., 1976) and HDL cholesterol ester (Drevon et al., 1977); in patients with familial LCAT deficiency cholesterol is deposited in tissues (Gjone, 1974); in hyperlipidaemic subjects body cholesterol pool size is a negative function of the plasma HDL cholesterol concentration (Miller et al., 1976).

High density lipoproteins are synthesised and secreted by the liver and small intestine. The newly secreted particles differ substantially from plasma HDL. As already indicated, the latter are spheres, rich in cholesterol ester and apoprotein AI. In contrast, the nascent forms are discoidal, being composed of a bilayer of phospholipid and unesterified cholesterol with virtually no cholesterol ester and with apoprotein $\mathrm{E}$ as the major peptide. Nascent HDL is also more reactive with LCAT and more effective in promoting cholesterol efflux from erythrocytes than is plasma HDL (Hamilton et al., 1976; Glomset, 1978).

Transformation of nascent HDL to plasma HDL appears to result principally from the esterification of cholesterol in HDL by the LCAT reaction and from the acquisition of $A$ apoproteins from nascent chylomicrons. Cholesterol ester molecules formed in nascent HDL undergo either of two fates: some are transferred, possibly in association with apoprotein E, to triglyceride-rich lipoproteins (see above); others move, on account of their non-polar nature, to occupy a position between the phospholipid bilayer of the particle. The resultant decrease in the ratio of unesterified cholesterol to phospholipid at the surface of the particles is presumed to promote the uptake of further unesterified cholesterol from cell membranes. This is in turn also esterified by LCAT, and the cycle is repeated, the discs being converted in the process to spheres of increasing core size and cholesterol ester content.

\section{Familial dyslipoproteinaemia}

Recent genetic and biochemical studies have greatly clarified the nature of the familial disorders of lipoprotein metabolism. Although much remains to be learnt, this knowledge has necessitated a revision of earlier approaches to their classification. The scheme developed by Fredrickson et al. (1967), and subsequently modified by the World Health Organization (1970), was a milestone in the study of lipid disorders, providing a basis for their systematic study by researchers and, at the same time, a convenient notation for clinicians as a guide to treatment. A number of weaknesses, however, arenow recognised in this system of classification. Firstly, several of the plasma lipoprotein patterns (types I-V), which provided the basis of the system, have been shown by recent epidemiological and metabolic studies not to be unique to a particular inborn error. Different genetic defects may produce the same lipoprotein pattern, albeit through different mechanisms. Similarly, the phenotypic expression of a particular genotype may vary, for example, according to body weight or to the nature of the diet. Secondly, a number of 'new' inborn errors (eg, familial hyperalphalipoproteinaemia) have been identified.Thirdly, the emphasis placed in the system on elevated plasma lipoprotein concentrations may be inappropriate. Most 'hyperlipoproteinaemias' are associated with a reduction of the concentration of one or more other lipoprotein classes, and in some instances this may be the more important aspect. For this reason I prefer the term 'dyslipoproteinaemia' to include all disturbances of lipoprotein metabolism.

Table 2 lists the major familial dyslipoproteinaemias at present recognised: their inheritance, biochemistry, and phenotypic expressions. It can be seen that the type I pattern, reflecting defective hydrolysis of chylomicron triglyceride, can result from an inherited deficiency of either lipoprotein lipase or its activator, apoprotein CII (Breckenridge et al., 1978). Similarly, the type IIa pattern, the most prominent feature of which is a high LDL concentration, can reflect either defective removal of LDL, as in familial hypercholesterolaemia (Langer et al., 1972), or overproduction of LDL by way of VLDL, as in familial combined hyperlipidaemia (Sigurdsson et al., $1976 \mathrm{a}, \mathrm{b})$. The phenotypic expression of familial combined hyperlipidaemia is partly determined by relative body weight (Brunzell et al., 1974). The type IV pattern (elevated VLDL concentration) is the usual phenotypic expression of familial combined hyperlipidaemia in obesity, as well as being the manifestation of the gene for familial hypertriglyceridaemia. When the latter condition leads to massive elevations of VLDL concentration, these 
Table 2 Familial dyslipoproteinaemias

\begin{tabular}{|c|c|c|c|}
\hline Genetic classification & Inheritance & $\begin{array}{l}\text { Disturbance of lipoprotein } \\
\text { metabolism }\end{array}$ & Plasma lipoprotein phenotype* \\
\hline $\begin{array}{l}\text { Familial lipoprotein lipase (LPL) } \\
\text { deficiency }\end{array}$ & Autosomal recessive & $\begin{array}{l}\text { Absence of LPL } \rightarrow \text { impaired } \\
\text { chylomicron catabolism }\end{array}$ & Type I \\
\hline Apoprotein CII deficiency & Autosomal recessive & $\begin{array}{l}\text { Absence of apo CII } \rightarrow \text { failure of } \\
\text { activation of } \mathrm{LPL} \rightarrow \text { impaired } \\
\text { chylomicron catabolism }\end{array}$ & Type I \\
\hline $\begin{array}{l}\text { Familial hypercholesterolaemia } \\
\text { (3 types) }\end{array}$ & Autosomal dominant & $\begin{array}{l}\text { Reduction/absence of LDL } \\
\text { receptors or failure of internalisation } \\
\text { of receptor-LDL complexes in } \\
\text { extrahepatic cells } \rightarrow \text { impaired LDL } \\
\text { catabolism }\end{array}$ & Type IIa \\
\hline Polygenic hypercholesterolaemia & Polygenic & Uncertain & Type IIa \\
\hline Familial combined hyperlipidaemia & Autosomal dominant & $\begin{array}{l}\text { Probably hepatic overproduction } \\
\text { of apo B } \rightarrow \text { increased VLDL secretion } \\
\text { and LDL production from VLDL }\end{array}$ & Type IIa, IIb, or IV \\
\hline Familial hypertriglyceridaemia & Autosomal dominant & $\begin{array}{l}\text { Probably hepatic overproduction of } \\
\text { triglyceride } \rightarrow \text { increased triglyceride } \\
\text { secretion in VLDL }\end{array}$ & Type IV or V \\
\hline Broad-beta disease & Uncertain & $\begin{array}{l}\text { Apoprotein EIII deficiency. Impaired } \\
\text { catabolism of chylomicron 'remnants' } \\
\text { and IDL }\end{array}$ & Type III \\
\hline Familial hyperalphalipoproteinaemia & Uncertain & Uncertain & Increased HDL concentration \\
\hline Abetalipoproteinaemia & Autosomal recessive & $\begin{array}{l}\text { Inability of liver and intestine to } \\
\text { synthesise apoB } \rightarrow \text { failure of } \\
\text { assembly of VLDL and chylomicrons }\end{array}$ & $\begin{array}{l}\text { Absence of chylomicrons, VLDL, } \\
\text { IDL, and LDL }\end{array}$ \\
\hline Familial hypobetalipoproteinaemia & Autosomal dominant & $\begin{array}{l}\text { Reduced apoB synthesis } \rightarrow \text { reduced } \\
\text { VLDL secretion and LDL production } \\
\text { from VLDL }\end{array}$ & Low VLDL and LDL concentrations \\
\hline Tangier disease & Autosomal recessive & $\begin{array}{l}\text { Enhanced apoprotein AI and AII } \\
\text { catabolism }\end{array}$ & $\begin{array}{l}\text { Low HDL concentration; accumula- } \\
\text { tion of remnants of chylomicron } \\
\text { catabolism }\end{array}$ \\
\hline $\begin{array}{l}\text { Familial lecithin: cholesterol } \\
\text { acyltransferase (LCAT) deficiency }\end{array}$ & Autosomal recessive & $\begin{array}{l}\text { Absence of LCAT } \rightarrow \text { failure of } \\
\text { cholesterol esterification in plasma } \\
\rightarrow \text { failure of maturation of nascent } \\
\text { HDL, and impaired triglyceride-rich } \\
\text { lipoprotein catabolism }\end{array}$ & $\begin{array}{l}\text { Presence of discoidal HDL; accumula- } \\
\text { tion of abnormal cholesterol-rich } \\
\text { remnants of chylomicron and VLDL } \\
\text { catabolism; lipoprotein-X }\end{array}$ \\
\hline
\end{tabular}

* Roman numerals refer to the lipoprotein phenotype according to the classification of the World Health Organization (1970)

interfere with the catabolism of chylomicrons, probably by competing for common removal mechanisms (Brunzell et al., 1973), resulting in a combined elevation of both lipoproteins. This appears to be the usual cause of the type $V$ pattern of the Fredrickson classification. It can occur when the condition is inherited from both parents, or when it is combined with a secondary hypertriglyceridaemia (eg, diabetes, alcohol, and oestrogens).

In recent years great progress has been made in our understanding of the inborn errors of metabolism that underlie the familial dyslipoproteinaemias. Familial hypercholesterolaemia has been clearly shown in an elegant series of studies by Goldstein and Brown $(1974,1977)$ to reflect a defect in the receptor-mediated uptake of LDL in peripheral cells. Much of this work was performed with cultures of human fibroblasts and lymphocytes. Three distinct forms have been identified: (i) receptor-negative, in which there is a $50 \%$ reduction (in the heterozygous form) or a complete absence (in the homozygous form) of cell surface receptors for LDL; (ii) receptordefective, in which in the homozygous state there is a $80-90 \%$ reduction of LDL receptor number; and (iii) receptor-mislocation, in which the number of receptors is normal, but they fail to aggregate in the 'coated pits' of the cell membrane, resulting in a reduced rate of endocytosis of receptor-LDL complexes (internalisation defect).

There have been two particularly significant developments in the study of broad-beta disease (familial type III hyperlipoproteinaemia), so-called because of the electrophoretic appearance produced by the predominant lipoprotein, referred to as beta VLDL. Metabolic studies have supported the thesis that this is associated with defective catabolism of chylomicron 'remnants' and IDL in the liver (Chait et al., 1977). Secondly, isoelectric focusing studies have revealed that the condition is invariably associated with an absence in plasma of a subcomponent (E III) of apoprotein E (Utermann et al., 1975). On its own, however, deficiency of apoprotein E III is insufficient to cause the type III phenotype, as it exists in about $1 \%$ of healthy normolipidaemic people. Thus it may require the combination of E-III deficiency and another unidentified factor to 
produce the abnormality in remnant catabolism. Thyroid function may be important in this regard: myxoedema, which can produce the type III lipoprotein pattern by itself, considerably aggravates the familial condition (Hazzard and Bierman, 1972).

The metabolic defects associated with familial hypertriglyceridaemia and familial combined hyperlipidaemia are not yet certain, but on current information it seems probable that the former is associated with excessive hepatic triglyceride synthesis (Brunzell et al., 1977) and the latter with overproduction of VLDL apoprotein B (Sigurdsson et al., 1976a, b).

The familial apoprotein deficiencies are of considerable interest as they provide insight into the functions of the various peptides. Abetalipoproteinaemia, characterised by an absence of apoprotein B synthesis, results in a failure of chylomicron and VLDL assembly. As a consequence, triglyceride accumulates in the liver and intestine, and there is an absence of apoprotein B-containing lipoproteins from plasma. Hypobetalipoproteinaemia, associated with reduced apoprotein B synthesis, is genetically distinct from abetalipoproteinaemia and usually does not result in the complications of that condition. Apoprotein C II deficiency is extremely rare and, as already considered, results in a failure of lipoprotein lipase activation.

Tangier disease, characterised by extremely low plasma concentrations of HDL, was for long assumed to be due to a genetically determined defect in apoprotein AI synthesis. However, the condition is now known to be associated, on the contrary, with excessive catabolism of apoprotein AI (Schaefer et al., 1976; Assmann, 1978). Thus it is possible that the hepatic secretion of nascent HDL (composed predominantly of apoprotein E, phospholipid, and cholesterol), and hence also reverse cholesterol transport, may be normal in Tangier patients. Certainly, plasma LCAT activity in vitro is only moderately reduced and HDL cholesterol ester turnover in vivo appears to be normal (Clifton-Bligh et al., 1972; Assmann, 1978). This may explain why the majority of tissues in Tangier patients do not appear to accumulate cholesterol esters, the visible deposits in the reticuloendothelial system perhaps reflecting phagocytosis of chylomicron and VLDL remnants (Herbert et al., 1978).

Familial LCAT deficiency results in the accumulation of unesterified cholesterol, rather than cholesterol ester, in a wide variety of tissues (Gjone, 1974). Plasma from such patients is characterised by the presence of discoidal nascent HDL particles (normally not detectable in peripheral blood), of abnormal products of triglyceride-rich lipoprotein catabolism, and of lipoprotein-X (see later). All of these lipoproteins are rich in unesterified cholesterol and poor in cholesterol ester (Glomset, 1978).

The relationships of the different familial dyslipoproteinaemias to atherosclerosis are of considerable clinical and pathological interest. There is no doubt that familial hypercholesterolaemia, polygenic hypercholesterolaemia, familial combined hyperlipidaemia, and broad-beta disease are associated with accelerated atherosclerosis. This may also be true of familial LCAT deficiency (Gjone, 1974). Familial hypertriglyceridaemia and lipoprotein lipase deficiency do not appear to accelerate atherogenesis (Brunzell et al., 1976). Hypobetalipoproteinaemia and hyperalphalipoproteinaemia are associated with a reduced risk of atherosclerotic vascular disease and with increased longevity (Glueck et al., 1976). These observations can be largely explained by the probable atherogenic nature of the low and intermediate density lipoproteins and of chylomicron 'remnants', due to deposition of cholesterol in the lesions, and a possible anti-atherogenic effect of HDL, related to a role in reverse cholesterol transport or to inhibition of LDL uptake (see above). Very low density lipoproteins, on the other hand, may have little direct effect on the disease process, although Zilversmit (1976) has suggested that they might be converted to atherogenic intermediate density particles at the surface of the vascular endothelium through the action of lipoprotein lipase.

The diagnosis of the familial dyslipoproteinaemias can usually be confirmed, after exclusion of secondary causes, by a combination of the clinical picture, lipoprotein fractionation, and electrophoresis, and screening of first-degree relatives. When doubt exists, however, special tests may be required. These include measurement of post-heparin plasma lipolytic activity (for lipoprotein lipase and apoprotein CII deficiency), assay of LDL receptor function in cultured fibroblasts or blood lymphocytes (for familial hypercholesterolaemia), measurement of apoprotein E-III by isoelectric focusing (for broad-beta disease), and therapeutic trial (eg, dietary fat restriction to distinguish between lipoprotein lipase deficiency and severe familial hypertriglyceridaemia). In some instances, immunoassays of apoproteins A, B, and C may also be useful.

\section{Secondary dyslipoproteinaemia}

A variety of diseases are known to produce disturbances of plasma lipoprotein metabolism, and the list has increased in recent years. The more important are presented in Table 3 . It can be seen that all the lipoprotein patterns described in the preceding section can be produced in this way. The biochemical factors underlying the dyslipopro- 
Table 3 The common secondary dyslipoproteinaemias

\begin{tabular}{|c|c|c|}
\hline Condition & Probable disturbance(s) of lipoprotein metabolism & Plasma lipoprotein phenotype* \\
\hline $\begin{array}{l}\text { Insulin-dependent diabetes } \\
\text { mellitus }\end{array}$ & Reduced chylomicron and VLDL catabolism & Type I, IV, or V \\
\hline Insulin-resistant diabetes mellitus & Increased VLDL synthesis & Type IIb, IV, or V \\
\hline Obesity & Increased VLDL synthesis & Type IIb or IV \\
\hline Alcohol & Increased VLDL and HDL synthesis & $\begin{array}{l}\text { Increased VLDL and HDL concentrations; } \\
\text { occasionally fasting chylomicronaemia }\end{array}$ \\
\hline Myxoedema & Reduced VLDL, IDL, and LDL catabolism & Type IIa, IIb, or III \\
\hline Chronic renal failure & $\begin{array}{l}\text { Increased synthesis and reduced catabolism of } \\
\text { VLDL }\end{array}$ & Type IV or V \\
\hline Nephrotic syndrome & $\begin{array}{l}\text { Increased synthesis and reduced catabolism of } \\
\text { VLDL; increased LDL production }\end{array}$ & Type IIa, IIb, IV, or V \\
\hline Chronic biliary obstruction & $\begin{array}{l}\text { Acquired LCAT deficiency; increased } \\
\text { cholesterol synthesis }\end{array}$ & Lipoprotein-X; discoidal nascent HDL \\
\hline Chronic hepatocellular failure & $\begin{array}{l}\text { Reduced VLDL and HDL synthesis; reduced } \\
\text { IDL catabolism }\end{array}$ & $\begin{array}{l}\text { Low VLDL, LDL, and HDL concentrations; } \\
\text { triglyceride-rich LDL }\end{array}$ \\
\hline Acute hepatitis & Acquired LCAT deficiency & Discoidal nascent HDL; triglyceride-rich LDL \\
\hline
\end{tabular}

* Roman numerals refer to the lipoprotein phenotype according to the classification of the World Health Organization (1970)

teinaemia are, in many cases, uncertain, but considerable progress has been made.

The mechanism of hyperlipidaemia in diabetes mellitus differs according to the type of diabetes. In the insulin-deficient (juvenile-onset) form there is reduced lipoprotein lipase activity as a direct consequence of insulin deficiency, producing a type I, IV, or V pattern. In contrast, in insulin-resistant diabetes, elevated plasma insulin levels stimulate hepatic triglyceride and VLDL synthesis, usually resulting in the type IV lipoprotein pattern. Both disturbances generally respond to adequate control of the diabetic state. Failure to do so may be due to coexistent familial hypertriglyceridaemia or renal disease. The mechanism of production of hypertriglyceridaemia in obesity appears to be a consequence of insulin-resistance (Olefsky et al., 1974; Pykälistö et al., 1975).

Liver disease can also be associated with several dyslipoproteinaemias. Chronic hepatocellular failure may produce changes compatible with minor impairment of chylomicron 'remnant' and IDL catabolism, possibly due to reduced hepatic triglyceride lipase activity, but does not usually result in hyperlipidaemia. Acute alcoholic hepatitis produces a transient but marked LCAT deficiency, producing a similar lipoprotein pattern to that associated with familial LCAT deficiency (Ragland et al., 1978). Plasma LCAT activity is also reduced in chronic cholestasis. In this situation, however, the appearance of lipoprotein- $X$ is usually the most marked feature, presumably due to the associated bile retention. Lipoprotein-X particles are discoidal, like nascent HDL, but are considerably larger. They are composed of lecithin, unesterified cholesterol, albumin, and $\mathbf{C}$ apoproteins. These changes are particulary marked in primary biliary cirrhosis, in which the presence of lipoprotein-X may lead to massive hypercholesterolaemia (McIntyre, 1978).

The hyperlipidaemia of nephrotic syndrome appears to be due partly to increased triglyceride synthesis and VLDL secretion and partly to reduced triglyceride hydrolysis. The former appears to be a consequence of the low colloid osmotic pressure associated with hypoalbuminaemia, the hypertriglyceridaemia being reduced by albumin or dextran infusions. The low lipolytic activity may be due to urinary loss of apoprotein CII. Disturbed lipoprotein metabolism, reflected in moderately elevated levels of VLDL and low HDL cholesterol concentrations, is now recognised to be a common complication of chronic renal failure also (Bagdade et al., 1976), possibly explaining the increased susceptibility to coronary disease, which is now a well documented complication of uraemia. Increased triglyceride synthesis (Cramp et al., 1977) and decreased hepatic triglyceride lipase activity (Bolzano et al., 1978) have recently been described in this condition.

The importance of ethanol as a cause of hypertriglyceridaemia, by stimulating hepatic VLDL triglyceride secretion, is well recognised. More recently, it has become acknowledged that a rise in the plasma HDL concentration is an even more consistent effect of alcohol (Johansson and Medhus, 1974). This is of interest as it represents a departure from the inverse relationship between VLDL and HDL concentrations that exists in most other situations (Miller and Miller, 1975). The mechanism by which alcohol increases HDL concentration is uncertain. One possibility is that it is secondary to enzyme induction in the liver, leading to increased HDL synthesis. In this context it is of interest that the HDL concentration is also increased by at least two other agents which induce proliferation of the 
hepatic smooth endoplasmic reticulum: chlorinated hydrocarbons (Carlson and Kolmodin-Hedman, 1972) and phenytoin (Nikkilä et al., 1978).

The effects of oral contraceptives on plasma lipoprotein levels have attracted considerable interest in recent years on account of their widespread use in a young healthy population, coupled with the epidemiological evidence for an increased risk of coronary disease associated with their use. Oestrogens tend to elevate plasma VLDL and HDL concentrations in premenopausal women. Progestogens, on the other hand, tend to have the opposite effect. The net effect of any oestrogenprogestogen combination on the plasma lipoprotein pattern depends upon the nature and doses of the two components (Bradley et al., 1978). Oral contraceptive usage by subjects with familial hypertriglyceridaemia may rarely produce massive hypertriglyceridaemia, complicated by acute pancreatitis (Brunzell and Schrott, 1973).

Recent awareness of the fact that different plasma lipoprotein fractions have different epidemiological relationships to coronary disease (see below) has stimulated interest in the effects of dietary components on the concentrations of individual lipoproteins rather than on the plasma total cholesterol and triglyceride concentrations. It is too early for many certain conclusions to be drawn, but a number of interesting observations have emerged, particularly with regard to HDL. These include the finding of a reduction of HDL synthesis and concentration during the consumption of diets of very high polyunsaturated fatty acid content (Shepherd et al., 1978). Cholesterol-rich diets, on the other hand, increase the plasma VLDL, IDL, LDL, and HDL 2 concentrations (Mistry et al., 1976). The rise in $\mathrm{HDL}_{2}$ reflects at least in part the appearance of a cholesterol- and apoprotein E-rich alpha-migrating lipoprotein $\left(\mathrm{HDL}_{\mathrm{c}}\right.$ ), probably derived from HDL-I (Mahley et al., 1978).

\section{Plasma lipoproteins and atherosclerosis}

Although several of the specific dyslipoproteinaemias described above are associated with a greatly increased risk of CHD, only a minority of patients with clinical CHD have such conditions (Goldstein et al., 1973). Thus, while it is important to treat these conditions vigorously when present, this will have little impact on the overall incidence of CHD in the total community. It is necessary, therefore, for the relationship between CHD and plasma lipid metabolism to be identified also in the remaining majority of 'normal' subjects. A notable recent development in this area has been a renewal of interest by epidemiologists and patho- logists in the independent relationships of different plasma lipoprotein fractions, rather than those of the plasma total cholesterol and triglyceride concentrations, to coronary atheroma. Epidemiological and clinical studies have confirmed that the welldocumented positive correlation between the plasma total cholesterol concentration and CHD reflects their underlying relationships to the plasma LDL concentration. There seems little doubt that this in turn reflects a direct atherogenic effect of LDL. The same studies also demonstrated an independent negative correlation between $\mathrm{CHD}$ and the plasma HDL cholesterol concentration. This finding has lent support to an earlier hypothesis, proposed by Miller and Miller (1975), that HDL may exert an anti-atherogenic effect by virtue of a role in reverse cholesterol transport, and that disturbed HDL metabolism may be a common cause of premature atherosclerosis.

The relationship of CHD prevalence to the plasma HDL cholesterol concentration has been the subject of two reports. In the Cooperative Lipoprotein Phenotyping Study (Castelli et al., 1977) data were analysed from 6859 men and women aged 40 years or more, living in five centres of the United States. In the combined data, CHD prevalence increased from 8 to 18 per 100 as HDL cholesterol decreased from $\geqslant 45$ to $\leqslant 25 \mathrm{mg} / \mathrm{dl}$. This association was independent of the plasma triglyceride and LDL cholesterol concentrations. Similar trends were observed in each centre, in both sexes, in all age groups, in different ethnic groups, and for both myocardial infarction and angina pectoris considered separately. In the Honolulu Heart Study (Rhoads et al., 1976), 2019 men of Japanese descent aged 50-72 years, including 264 cases of CHD, were examined. CHD prevalence showed more than a two fold rise between the highest $(\geqslant 53 \mathrm{mg} / \mathrm{dl})$ and the lowest $(\leqslant 36 \mathrm{mg} / \mathrm{dl})$ quartiles of HDL cholesterol, which was again independent of the plasma triglyceride and LDL cholesterol concentrations. These two studies established that patients with clinically manifest CHD tend to have a low HDL cholesterol concentration independently of other lipoproteins.

The predictive power of HDL cholesterol concentration for clinical CHD, independently of other lipoproteins and risk factors, was examined as part of the Tromsø Heart Study in Norway and the Framingham Study in the United States. In the Tromsø Study, Miller et al. (1977b) followed 6595 men aged 20-49 years for two years, during which time 21 of the participants developed a new coronary event (myocardial infarction or sudden death). For each of these cases two control subjects were randomly selected, matched for age, ethnic origin, 
area of residence, and physical activity. The mean HDL cholesterol concentration in the cases was found to be significantly lower than that in the controls, while the converse was true for the cholesterol concentration in lipoproteins of lower density $(\mathrm{d}<1.063 \mathrm{~g} / \mathrm{ml})$. Discriminant function analysis revealed that the relationships of coronary risk to HDL cholesterol and $d<1.063$ cholesterol were independent of each other and of plasma triglyceride (non-fasting), blood pressure, cigarette consumption, and relative body weight. Furthermore, the contribution of HDL cholesterol to the discrimination between cases and controls was greater than that of density $<1.063 \mathrm{~g} / \mathrm{ml}$ cholesterol.

Essentially identical results were reported by the Framingham group (Gordon et al., 1977) after following for two to eight years 1025 men and 1445 women aged 49-82 years, all of whom had initially been free of clinical CHD. CHD incidence per 1000 subjects increased from 25 to 105 in men and from 14 to 164 in women as HDL cholesterol decreased from $65-74$ to $25-34 \mathrm{mg} / \mathrm{dl}$ (Fig. 2). In both sexes this association was again independent of the plasma triglyceride (fasting) and LDL cholesterol concentrations, blood pressure, cigarette consumption, and relative body weight. It applied to each 10 -year age group and to all categories of CHD examined. On the basis of the likelihood ratio statistic, the pre- dictive power of HDL cholesterol was substantially greater than that of LDL cholesterol.

Three additional prospective studies of HDL in relation to CHD have since been completed. In the Oslo Heart Study (Enger et al., 1979), 93 men aged 40-49 years who suffered a first myocardial infarction during five years of follow-up had a significantly lower mean HDL cholesterol concentration (in frozen serum samples) than did 186 controls matched for age, smoking habits, time of blood sampling, and serum total cholesterol and triglyceride (nonfasting) concentrations. In the Israeli Ischaemic Heart Disease Study of approximately 6500 men aged 40 years or more at entry, a low HDL cholesterol concentration was associated with an increased risk of first myocardial infarction during five years of follow-up, independently of plasma total cholesterol, age, relative body weight, cigarette consumption, blood pressure, and glucose tolerance (Goldbourt and Medalie, 1979). In a further examination of the Tromsø participants, the serum concentration of apolipoprotein AI, the major HDL peptide, was also significantly lower in the cases than in the controls (Ishikawa et al., 1978). Evidence has also been presented that cerebral (Rössner et al., 1978) and peripheral (Bradby et al., 1978) atherosclerosis are associated with low HDL concentrations independently of other lipoproteins.

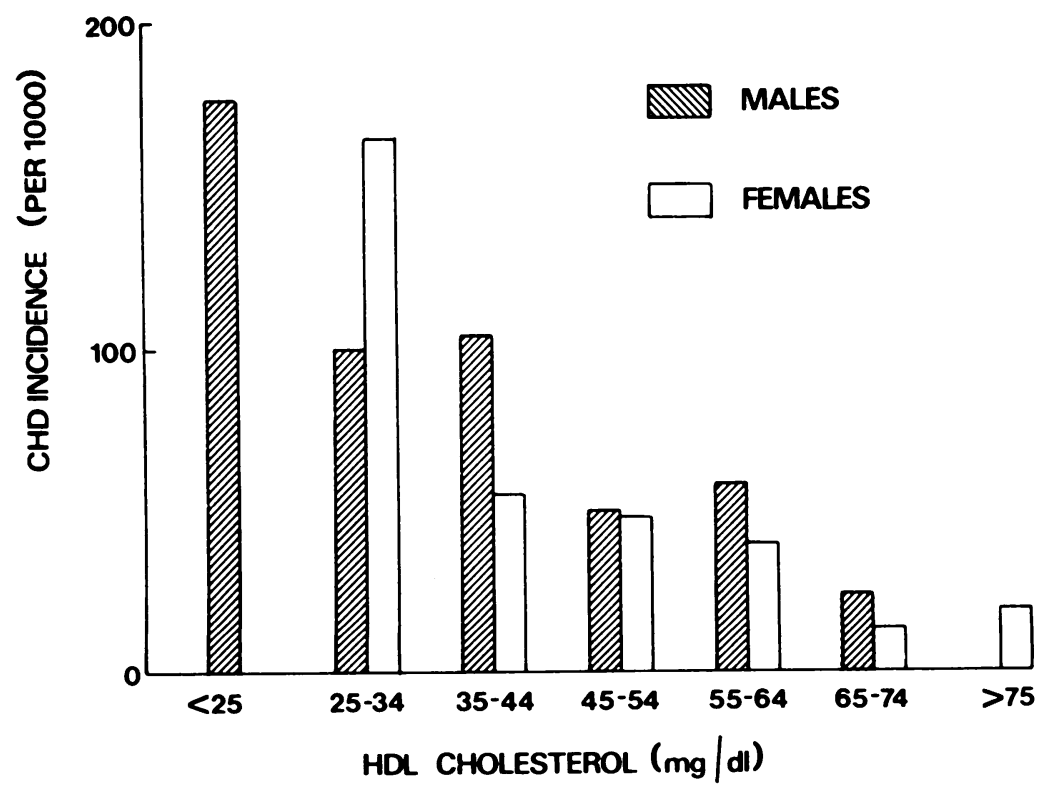

Fig. 2 Incidence of clinical coronary heart disease during four years (mean) of follow-up as a function of the initial plasma high density lipoprotein cholesterol concentration in the Framingham Study (data from Gordon et al., 1977). Modified from Miller (1978). 
Evidence that the correlation between HDL concentration and coronary risk reflects an underlying relationship to coronary atherosclerosis has been provided by angiographic studies. Pearson $e t$ al. (1979), for example, studied coronary angiograms from 483 men and women, most of whom were being investigated for chest pain. Three major conclusions were drawn: firstly, that in both sexes patients with coronary disease had a lower HDL cholesterol concentration than those without; secondly, that within the diseased group, patients with left main artery disease had the lowest HDL cholesterol levels; and, thirdly, that among the remaining subjects, the number of vessels diseased was a negative function of the HDL cholesterol concentration. Jenkins et al. (1978) quantified coronary atherosclerosis in angiograms from 41 patients undergoing investigation for chest pain. A coronary atherosclerosis score, based on the number and severity of lesions in eight proximal segments of the coronary circulation, showed a strong inverse relationship to the plasma HDL cholesterol concentration. On multivariate analysis this correlation was found to be independent of age and of the VLDL and LDL concentrations.

In all of the investigations reported to date in which multivariate statistical procedures were employed, any positive correlation between clinical CHD or coronary atherosclerosis and the plasma total or VLDL-triglyceride concentration on single variate analysis was found to be indirect and dependent upon a well-recognised negative correlation between VLDL triglyceride and HDL cholesterol, contrasting with the relationship of CHD to LDL cholesterol concentration, which was uniformly independent of HDL. This suggests that VLDL itself may not be directly atherogenic. It does not exclude the possibility, however, that disturbed plasma triglyceride transport may be the primary factor responsible for the reduction of HDL concentration in some coronary prone subjects. Indeed, the evidence, referred to above, for the origin of some HDL components from triglyceride-rich lipoproteins, and for other links between the metabolism of HDL and VLDL, lend strength to such a possibility. The precise relationship of HDL to cholesterol and triglyceride transport and to atherogenesis promises to be an exciting area of future research.

\section{References}

Assmann, G. (1978). The metabolic role of high density lipoproteins: perspectives from Tangier disease. In High Density Lipoproteins and Atherosclerosis, edited by A. M. Gotto Jr., N. E. Miller, and M. F. Oliver, pp. 77-88. Elsevier, Amsterdam.
Bagdade, J., Casaretto, A., and Albers, J. (1976). Effects of chronic uremia, hemodialysis, and renal transplantation on plasma lipids and lipoproteins in man. Journal of Laboratory and Clinical Medicine, 87, 37-48.

Bolzano, K., Krempler, F., and Sandhofer, F. (1978). Hepatic and extrahepatic triglyceride lipase activity in uraemic patients on chronic haemodialysis. European Journal of Clinical Investigation, 8, 289-293.

Bradby, G. V. H., Valente, A. J., and Walton, K. W. (1978). Serum high-density lipoproteins in peripheral vascular disease. Lancet, 2, 1271-1274.

Bradley, D. D., Wingerd, J., Petitti, D. B., Krauss, R. M., and Ramcharan, S. (1978). Serum high-densitylipoprotein cholesterol in women using oral contraceptives, estrogens and progestins. New England Journal of Medicine, 299, 17-20.

Bradley, W. A., and Gotto, A. M. Jr. (1978). Structure of intact human plasma lipoproteins. In Disturbances in Lipid and Lipoprotein Metabolism, edited by J. M. Dietschy, A. M. Gotto Jr., and J. A. Ontko, pp. 111137. American Physiological Society, Bethesda, Md.

Breckenridge, W. C., Little, J. A., Steiner, G., Chow, A., and Poapst, M. (1978). Hypertriglyceridemia associated with deficiency of apolipoprotein C-II. New England Journal of Medicine, 298, 1265-1273.

Brunzell, J. D., Chait, A., Goldberg, A. P., and Albers, J. J. (1977). Monogenic familial hypertriglyceridemia vs familial combined hyperlipidemia: evidence for overproduction of triglyceride in familial hypertriglyceridemia (Abstract). Clinical Research, 25, 338A.

Brunzell, J. D., Hazzard, W. R., Motulsky, A. G., and Bierman, E. L. (1974). Role of obesity in phenotypic expression of familial combined hyperlipidemia (Abstract). Clinical Research, 22, 462A.

Brunzell, J. D., Hazzard, W. R., Porte, D. Jr., and Bierman, E. L. (1973). Evidence for a common, saturable, triglyceride removal mechanism for chylomicrons and very low density lipoproteins in man. Journal of Clinical Investigation, 52, 1578-1585.

Brunzell, J. D., and Schrott, H. G. (1973). The interaction of familial and secondary causes of hypertriglyceridemia: role in pancreatitis. Transactions of the Association of American Physicians, 86, 245-254.

Brunzell, J. D., Schrott, H. G., Motulsky, A. G., and Bierman, E. L. (1976). Myocardial infarction in the familial forms of hypertriglyceridemia. Metabolism, 25, 313-320.

Carlson, L. A., and Kolmodin-Hedman, B. (1972). Hyper-a-lipoproteinaemia in men exposed to chlorinated hydrocarbon pesticides. Acta Medica Scandinavica, 192, 29-32

Castelli, W. P., Doyle, J. T., Gordon, T., Hames, C. G., Hjortland, M. C., Hulley, S. B., Kagan, A., and Zukel, W. J. (1977). HDL cholesterol and other lipids in coronary heart disease. The Cooperative Lipoprotein Phenotyping Study. Circulation, 55, 767-772.

Chait, A., Brunzell, J. D., Albers, J. J., and Hazzard, W. R. (1977). Type III hyperlipoproteinemia ('remnant removal disease'): insight into the pathogenetic mechanism. Lancet, 1, 1176-1178.

Clifton-Bligh, P., Nestel, P. J., and Whyte, H. M. (1972). 
Tangier disease. Report of a case and studies of lipid metabolism. New England Journal of Medicine, 286, 567-571.

Cramp, D. G., Tickner, T. R., Beale, D. J., Moorhead, J. F., and Wills, M. R. (1977). Plasma triglyceride secretion and metabolism in chronic renal failure. Clinica Chimica Acta, 76, 237-241.

Drevon, C. A., Berg, T., and Norum, K. R. (1977). Uptake and degradation of cholesterol-ester-labelled rat plasma lipoproteins in purified rat hepatocytes and nonparenchymal liver cells. Biochimica et Biophysica Acta, 287, 122-136.

Enger, S. C., Hjermann, I., Foss, O. P., Helgeland, A., Holme, I., Leren, P., and Norum, K. R. (1979). High density lipoprotein cholesterol and myocardial infarction or sudden coronary death: a prospective casecontrol study in middle-aged men of the Oslo Study. Artery, 5, 170-181.

Fredrickson, D. S., Levy, R. I., and Lees, R. S. (1967). Fat transport in lipoproteins-an integrated approach to mechanisms and disorders. New England Journal of Medicine, 276, 34-44.

Gjone, E. (1974). Familial lecithin: cholesterol acyltransferase deficiency-a clinical survey. Scandinavian Journal of Clinical and Laboratory Investigation, 33, Supplement 137, 73-82.

Glomset, J. A. (1970). Physiological role of lecithin cholesterol acyltransferase. American Journal of Clinical Nutrition, 23, 1129-1136.

Glomset, J. A. (1978). High density lipoproteins in familial LCAT deficiency. In High Density Lipoproteins and Atherosclerosis, edited by A. M. Gotto Jr., N. E. Miller, and M. F. Oliver, pp. 57-65. Elsevier, Amsterdam.

Glueck, C. J., Gartside, P., Fallat, R. W., Sielski, J., and Steiner, P. M. (1976). Longevity syndromes-familial hypobeta- and familial hyperalphalipoproteinemia. Journal of Laboratory and Clinical Medicine, 88, 941-957.

Goldbourt U., and Medalie, J. H. (1979). High density lipoprotein cholesterol and incidence of coronary heart disease-the Israeli Ischaemic Heart Disease Study. American Journal of Epidemiology, 109, 296-308.

Goldstein, J. L., and Brown, M. S. (1974). Binding and degradation of low density lipoproteins by cultured human fibroblasts. Journal of Biological Chemistry, 249, 5153-5162.

Goldstein, J. L., and Brown, M. S. (1977). The low-density lipoprotein pathway and its relation to atherosclerosis. Annual Review of Biochemistry, 46, 897-930.

Goldstein, J. L., Schrott, H. G., Hazzard, W. R., Bierman, E. L., and Motulsky, A. G. (1973). Hyperlipidemia in coronary heart disease. II. Genetic analysis of lipid levels in $\mathbf{1 7 6}$ families and delineation of a new inherited disorder, combined hyperlipidemia. Journal of Clinical Investigation, 52, 1544-1568.

Gordon, T., Castelli, W. P., Hjortland, M. C., Kannel, W. B., and Dawber, T. R. (1977). High density lipoprotein as a protective factor against coronary heart disease. American Journal of Medicine, 62, 707-714.

Hamilton, R. L., Williams, M. C., Fielding, C. J., and Havel, R. J., (1976). Discoidal bilayer structure of nascent high density lipoproteins from perfused rat liver. Journal of Clinical Investigation, 58, 667-680.

Havel, R. J. (1978). Metabolism of high density lipoprotein. Origin of HDL. In High Density Lipoproteins and Atherosclerosis, edited by A. M. Gotto Jr., N. E. Miller, and M. F. Oliver, pp. 21-35. Elsevier, Amsterdam.

Hazzard, W. R., and Bierman, E. L. (1972). Aggravation of broad- $\beta$ disease (type 3 hyperlipoproteinemia) by hypothyroidism. Archives of Internal Medicine, 130, 822-828.

Herbert, P. N., Forte, T., Heinen, R. J., and Fredrickson, D. S. (1978). Tangier disease: one explanation of lipid storage. New England Journal of Medicine, 299, 519-521.

Innerarity, T. L., Mahley, R. W., Weisgraber, K. H., and Bersot, T. P. (1978). Apoprotein (E-A-II) complex of human plasma lipoproteins. II. Receptor binding activity of a high density lipoprotein subfraction modulated by the apo (E-A-II) complex. Journal of Biological Chemistry, 253, 6289-6295.

Ishikawa, T., Fidge, N., Thelle, D. S., Førde, O. H., and Miller, N. E. (1978). The Tromsø Heart Study: serum apolipoprotein AI concentration in relation to future coronary heart disease. European Journal of Clinical Investigation, 8, 179-182.

Jenkins, P. J., Harper, R. W., and Nestel, P. J. (1978). Severity of coronary atherosclerosis related to lipoprotein concentration. British Medical Journal, 2, 388-391.

Johansson, B. G., and Medhus, A. (1974). Increase in plasma $\alpha$-lipoproteins in chronic alcoholics after acute abuse. Acta Medica Scandinavica, 195, 273-277.

Langer, T., Strober, W., and Levy, R. I. (1972). The metabolism of low density lipoprotein in familial type II hyperlipoproteinemia. Journal of Clinical Investigation, 51, 1528-1536.

McGowan, G. K., and Walters, G. (Eds) (1973). Disorders of lipid metabolism. Journal of Clinical Pathology, 26, Supplement, 5.

McIntyre, N. (1978). Plasma lipids and lipoproteins in liver disease. Gut, 19, 526-530.

Mahley, R. W., Innerarity, T. L., Bersot, T. P., Lipson, A., and Margolis, S. (1978). Alterations in human high-density lipoproteins, with or without increased plasma-cholesterol, induced by diets high in cholesterol. Lancet, 2, 807-809.

Miller, N. E. (1978). The evidence for the antiatherogenicity of high density lipoprotein in man. Lipids, 13, 914-919.

Miller, G. J., and Miller, N. E. (1975). Plasma-highdensity-lipoprotein concentration and development of ischaemic heart disease. Lancet, 1, 16-19.

Miller, N. E., Førde, O. H., Thelle, D. S., and Mjøs, O. D. (1977b). The Tromsø Heart Study. High-density lipoprotein and coronary heart disease: a prospective case-control study. Lancet, 1, 965-968.

Miller, N. E., Nestel, P. J., and Clifton-Bligh, P. (1976). Relationships between plasma lipoprotein cholesterol concentrations and the pool size and metabolism of cholesterol in man. Atherosclerosis, 23, 535-547.

Miller, N. E., Weinstein, D. B., Carew, T. E., Koschinsky, T., and Steinberg, D. (1977a). Interaction between high 
density and low density lipoproteins during uptake and degradation by cultured human fibroblasts. Journal of Clinical Investigation, 60, 78-88.

Mistry, P., Nicoll, A., Niehaus, C., Christie, I., Janus, E., and Lewis, B. (1976). Cholesterol feeding revisited (Abstract). Circulation, 53, Supplement 2, 178.

Nakai, T., Otto, P. S., Kennedy, D. L., and Whayne, T. F. Jr. (1976). Rat high density lipoprotein subfraction $\left(\mathrm{HDL}_{3}\right)$ uptake and catabolism by isolated rat liver parenchymal cells. Journal of Biological Chemistry, 251, 4914-4921.

Nikkilä, E. A., Kaste, M., Ehnholm, C., and Viikari, J. (1978). Increase of serum high-density lipoprotein in phenytoin users. British Medical Journal, 3, 99.

Olefsky, J. M., Farquhar, J. W., and Reaven, G. M. (1974). Reappraisal of the role of insulin in hypertriglyceridemia. American Journal of Medicine, 57, 551-560.

Patsch, J. R., Gotto, A. M. Jr., Olivecrona. T., and Eisenberg, S. (1978). Formation of high density lipoprotein $_{\mathbf{2}}$-like particles during lipolysis of very low density lipoproteins in vitro. Proceedings of the National Academy of Sciences of the United States of America, 75, 4519-4523.

Pearson, T. A., Bulkley, B. H., Achuff, S. C., Kwiterovich, P. O., and Gordis, L. (1979). The association of low levels of HDL cholesterol and arteriographically defined coronary artery disease. American Journal of Epidemiology, 109, 285-295.

Pykälistö O. J., Smith, P. H., and Brunzell, J. D. (1975). Determinants of human adipose tissue lipoprotein lipase. Effect of diabetes and obesity on basal- and diet-induced activity Journal of Clinical Investigation, 56, 1108-1117.

Ragland, J. B., Bertram, P. D., and Sabesin, S. M. (1978). Identification of nascent high density lipoproteins containing arginine-rich protein in human plasma. Biochemical and Biophysical Research Communications, 80, 81-88.

Rhoads, G. G., Gulbrandsen, C. L., and Kagan, A. (1976). Serum lipoproteins and coronary heart disease in a population study of Hawaii Japanese men. New England Journal of Medicine, 294, 293-298.

Rössner, S., Kjellin, K. G., Mettinger, K. L., Sidén, A., and Söderström, C. E. (1978). Normal serum-cholesterol but low H.D.L.-cholesterol concentration in young patients with ischaemic cerebrovascular disease. Lancet, 1, 577-579.

Schaefer, E. J., Blum, C. B., Levy, R. I., Goebel, R., Brewer, H. B., and Berman, M. (1976). High density lipoprotein metabolism in Tangier disease (Abstract). Circulation, 54, Supplement 2, 27.

Schaefer, E. J., Jenkins, L. L., and Brewer, H. B. Jr. (1978). Human chylomicron apolipoprotein metabolism. Biochemical and Biophysical Research Communications, 80, 405-412.

Shepherd, J., Packard, C. J., Patsch, J. R., Gotto, A. M. Jr., and Taunton, O. D. (1978). Effects of dietary polyunsaturated and saturated fat on the properties of high density lipoproteins and the metabolism of apolipoprotein A-I. Journal of Clinical Investigation, 61, 1582-1592.

Sigurdsson, G., Nicoll, A., and Lewis, B. (1975). Conversion of very low density lipoprotein to low density lipoprotein: a metabolic study of apolipoprotein B kinetics in human subjects. Journal of Clinical Investigation, 56, 1481-1490.

Sigurdsson, G., Nicoll, A., and Lewis, B. (1976a). The metabolism of low density lipoprotein in endogenous hypertriglyceridaemia. European Journal of Clinical Investigation, 6, 151-158.

Sigurdsson, G., Nicoll, A., and Lewis, B. (1976b). Metabolism of very low density lipoproteins in hyperlipidaemia: studies of apolipoprotein B kinetics in man. European Journal of Clinical Investigation, 6, 167-177.

Utermann, G., Jaeschke, M., and Menzel, J. (1975). Familial hyperlipoproteinemia type III: deficiency of a specific apolipoprotein (apo E-III) in the very lowdensity-lipoproteins. FEBS Letters, 56, 352-355.

World Health Organization (1970). Classification of hyperlipidaemias and hyperlipoproteinaemias. Bulletin of the World Health Organisation, 43, 891-915.

Zilversmit, D. B. (1976). Role of triglyceride-rich lipoproteins in atherogenesis. Annals of the New York Academy of Sciences, 275, 138-144.

Requests for reprints to: Dr N. E. Miller, Department of Chemical Pathology and Metabolic Disorders, St Thomas's Hospital Medical School, London SE1 7EH. 